Available online at https://jurnal.stmikroyal.ac.id/index.php/jurdimas

\title{
PENDAMPINGAN PELATIHAN SOFTWARE APLIKASI GUNA PERSIAPAN LKS DI SMK MUHAMMADIYAH SALAM
}

\author{
Emilya Ully Artha*1, Dimas Sasongko ${ }^{2}$ \\ ${ }^{1,2}$ S1 Teknik Informatika, Universitas Muhammadiyah Magelang \\ email:*ully@ummgl.ac.id
}

\begin{abstract}
Community service activities carried out at Muhammadiyah Salam Vocational School (SMK Muhammadiyah Salam), Salam Subdistrict, Magelang Regency so that the X grade $\left(1^{\text {st }}\right)$ students of Muhammadiyah Salam Vocational School can support computer creativity specifically for desktop applications for developing Software Engineering (RPL) skills. This service activity is carried out by using a method of mentoring for class X students through computer assistance / application programs such as database and desktop creation. The long-term goal is the preparation of class X students who have an interest in application software to participate in the Student Skills Competition (LKS) in the following period. This application software training at Muhammadiyah Vocational School does not have an RPL major, so students are selected to take part in this activity. The final output that will support this activity is student assistance in computer applications as a development aid for students in the field of programming / software engineering. In addition, the publication of the results of this service was in the community service journal
\end{abstract}

Keywords: Community Service, Software Engineering, Application Software, Programming

\begin{abstract}
Abstrak: Kegiatan pengabdian masyarakat yang dilakukan di SMK Muhammadiyah Salam, Kecamatan Salam Kabupaten Magelang bertujuan agar para siswa kelas X SMK Muhammadiyah Salam dapat memiliki kreatifitas pada bidang komputer khususnya aplikasi desktop untuk pengembangan ketrampilan Rekayasa Perangkat Lunak (RPL). Kegiatan pengabdian ini dilaksanakan dengan menggunakan metode pendampingan secara komprehensif kepada pada siswa kelas X melalui pendampingan program/aplikasi komputer seperti pembuatan database dan desktop. Tujuan jangka panjangnya adalah mempersiapkan siswa kelas $\mathrm{X}$ yang mempunyai minat di bidang software aplikasi untuk mengikuti kegiatan Lomba Kompetensi Siswa (LKS) pada periode berikutnya. Pelatihan software aplikasi ini karena di SMK Muhammadiyah tidak memiliki jurusan RPL, sehingga mahasiswa diseleksi untuk mengikuti kegiatan ini. Luaran akhir yang akan dicapai dari kegiatan ini adalah meningkatnya kemampuan siswa dalam penggunaan aplikasi komputer sebagai alat pengembangan kreatifitas siswa dalam bidang pemrograman/rekayasa perangkat lunak. Selain itu adalah terpublikasinya hasil pengabdian ini dalam jurnal pengabdian masyarakat.
\end{abstract}

Kata kunci: Pengabdian Masyarakat, Rekayasa Perangkat Lunak, Software Aplikasi, Pemrograman 
Jurdimas (Jurnal Pengabdian Kepada Masyarakat) Royal

Vol. 3 No. 1, Januari 2020, hlm. 27 - 30

DOI: https://doi.org/10.33330/jurdimas.v3i1.336

ISSN 2622-3813 (Online)

Available online at https://jurnal.stmikroyal.ac.id/index.php/jurdimas

\section{PENDAHULUAN}

Sekolah Menengah Kejuruan (SMK) Muhammadiyah Salam merupakan salah satu amal usaha pendidikan Yayasan Muhammadiyah yang terletak di Kecamatan Salam, Kabupaten Magelang dan di Provinsi Jawa Tengah. SMK Muhammadiyah Salam saat ini memiliki beberapa kompetensi keahlian yaitu Teknik Permesinan. Teknik Kendaraan Ringan, Teknik Komputer dan Jaringan, Teknik Gambar Bangunan dan Teknik Geologi Pertambangan.

Khusus kompetensi Teknik komputer dan Jaringan ini adalah keahlian yang berhubungan dengan Teknik Informatika di Universitas Muhammadiyah Magelang. Saat ini Lomba Kompetensi Siswa (LKS) yang diadakan di tiap kabupaten dituntut tidak hanya keahlian Teknik Komputer dan Jaringan saja melainkan semua ketrampilan yang berhubungan dengan Teknik informatika seperti multimedia, animasi dan rekayasa perangkat lunak. Karena tidak memiliki kompetensi pada bidang rekayasa perangkat lunak, maka LKS yang sering diikuti tidak pernah dilaksanakan secara tuntas dan belum pernah memenangi lomba di tingkat kabupaten.

Berdasarkan hasil pengamatan pada saat mengikuti LKS dengan beberapa siswa dan sekolah di lokasi pada kunjungan awal, terungkap bahwa sebagian besar siswa belum siap untuk mengikuti lomba LKS. Persiapan yang apa adanya mengakibatkan munculnya rasa ketidakpercayaan pada lomba bidang rekayasa perangkat lunak (RPL) (Badri 2016). Sehingga siswa yang ditunjuk untuk mengikuti lomba LKS bidan RPL tidak dapat menyelesaikannya secara tuntas.

Berdasarkan analisis situasi yang ada, teridentifikasi beberapa hasil identifikasi permasalahan mitra yang didapatkan dari pengamatan dan hasil wawancara langsung diantaranya adalah terdapatnya persepsi dan gap terhadap tingkat kemampuan dalam mempelajari penggunaan perangkat teknologi, para siswa cenderung merasa tidak memiliki kemampuan untuk mempelajari perangkat komputer dan software aplikasinya. Serta masalah kesempatan dan keinginan untuk mempelajari perangkat teknologi komputer beserta software aplikasinya belum mendapatkan prioritas pada saat LKS berlangsung. Hal ini disebabkan faktor kemampuan guru yang tidak mempunyai latar belakang pembuatan rekayasa perangkat lunak dan waktu persiapan yang singkat untuk melatih para murid yang akan mengikuti pelatihanpelatihan terkait sangat minim. Spesifikasi komputer yang terdapat pada laboratorium juga sangat minim karena tidak semua komputer dan laptop memenuhi standar minimal.

Dari hasil olah identifikasi masalah mitra tersebut ditemukan permasalahan utama mitra/siswa yang menjadi permasalahan prioritas yang harus ditangani yakni kesempatan untuk memperoleh pelatihan-pelatihan yang sangat diharapkan oleh mitra dalam upaya mengembangkan bakat kreatifitas siswa dalam bidang pengembangan rekayasa perangkat lunak sebagai persiapan mengikuti kegiatan LKS.

\section{METODE}

Berdasar pada analisis situasi, kondisi obyektif yang ada pada mitra, dan solusi yang disepakati bersama, maka pendekatan masalahnya disajikan dalam gambar 1.

Kegiatan Pengabdian kepada Masyarakat ini dilaksanakan dalam waktu 3 (tiga) bulan terbagi dalam lima tahap yaitu : (1) tahap perumusan , (2) tahap penentuan solusi, (3) metode penyelesaian, (4) tahap evaluasi, dan (5) output (Badri, 2016).

\section{A. Tahap Perumusan Masalah}

Pada tahap ini adalah untuk koordinasi tim pengabdian masyarakat Universitas Muhammadiyah Magelang dengan masyarakat sasaran, yaitu Kepala Sekolah SMK Muhammadiyah Salam dan guru beserta laboran komputer, membahas tentang rumusan masalah yang ada, rencana 
Jurdimas (Jurnal Pengabdian Kepada Masyarakat) Royal

Vol. 3 No. 1, Januari 2020, hlm. 27 - 30

DOI: https://doi.org/10.33330/jurdimas.v3i1.336

ISSN 2622-3813 (Online)

Available online at https://jurnal.stmikroyal.ac.id/index.php/jurdimas

kegiatan pelatihan dan tujuan dilakukan pelatihan tersebut.

\section{B. Tahap Penentuan Solusi}

Pada tahap ini tim pengabdian akan memberikan beberapa solusi untuk menyelesaikan masalah yang terjadi di SMK Muhammadiyah Salam. Solusi yang diberikan adalah untuk memberikan pelatihan kepada siswa untuk melaksanakan pelatihan software aplikasi kepada para siswa kelas X di SMK Muhammadiyah Salama keahlian Teknik Komputer dan Jaringan.

\section{Metode Penyelesaian}

Pada tahap ini tim pengabdian akan memberikan pelatihan software aplikasi dalam bentuk DBMS (Database Management System) menggunakan MySQL. Namun sebelum ke pelatihan, kami memberikan keunggulan jika siswa dapat mempunyai keahlian di bidang software aplikasi. Pertemuan awal para siswa melakukan instalasi program DBMS MySQL di komputer laboratorium. Instalasi ini bertujuan agar para siswa dapat mengetahui proses dan cara melakukan instalasi MySQL. Setelah instalasi selesai para siswa membuat sebuah database sekolah yang digunakan sebagai database untuk latihan. Dilanjutkan dengan membuat 3 tabel yaitu siswa, guru, maple. Target dari pelatihan ini adalah para siswa dapat menampilkan data yang sudah disimpan untuk menjadi sebuah informasi yang berguna.

\section{Tahap Evaluasi}

Pada tahap ini, tim pengabdian akan membuat soal yang isinya hamper sama dengan soal LKS secara bertahap, soal yang dibuat meliputi pembuatan database dan tabel yang akan dipakai untuk pembuatan program aplikasi, nantinya beberapa siswa yang memiliki nilai tertinggi akan didampingi secara intens untuk diikutkan dalam persiapan lomba LKS. Bersama para guru pendamping nantinya para siswa yang lolos persiapan akan didampingi dalam pelatihan pembuatan program.

E. Output

a. Pada tahap terakhir yaitu untuk penyusunan output pelatihan berupa :

b. Siswa dapat membuat database, table dan mengisi data. Serta interface menggunakan aplikasi .Net

c. Siswa menggunakan database MySQL untuk mempelajari perintah-perintah SQL(Duh \& Kirchhoff, 2011).

d. Siswa diharapkan dapat mengikuti seleksi untuk persiapan lomba LKS.

e. Membuat aplikasi/program sederhana.

f. Peningkatan kualitas siswa sebagai tambahan ilmu yang didapatkan di sekolah

g. Siswa dapat mengoperasikan aplikasi komputer DBMS/program aplikasi untuk membuat program

h. Publikasi Media Elektronik, dengan situs berita online tentang pendidikan.

\section{PEMBAHASAN}

Kegiatan PKU yang dilaksanakan pada siswa SMM Muhammadiyah Salam Magelang, telah berlangsung dengan cukup baik. Hal ini terlihat dari tingkat partisipasi siswa untuk mengikuti kegiatan pelatihan sangat tinggi. Siswa menyambut positif kegiatan yang telah dilakukan. Mereka sangat mengharapkan adanya kegiatan-kegiatan yang sifatnya memberikan tambahan ilmu pada siswa yang tidak didapatkan pada kelas. Kepala Sekolah dan guru pendampung juga menyambut antusias terkait pelaksanaan kegiatan ini dan berharap kegiatan dapat dilakukan secara kontinu untuk membantu meningkatkan kualitas siswa. Dalam kegiatan pelatihan, para siswa sangat antusias untuk mengikuti kegiatan pengabdian ini, terbukti siswa sudah dapat membuat database dan tabel serta dapat memahami perintahperintah SQL.

Peserta dalam kegiatan PKU ini adalah para siswa kelas X dari SMK Muhammadiyah Salam jurusan Teknik Komputer dan 
Available online at https://jurnal.stmikroyal.ac.id/index.php/jurdimas

Jaringan (TKJ). Siswa yang hadir ada 10 orang, dan 2 guru pendamping. Dalam pelatihan tersebut yang dilaksanakan dalam 7 (tujuh) kali pertemuan, peserta diajarkan materi mengenai database management system (DBMS) menggunakan software MySQL.

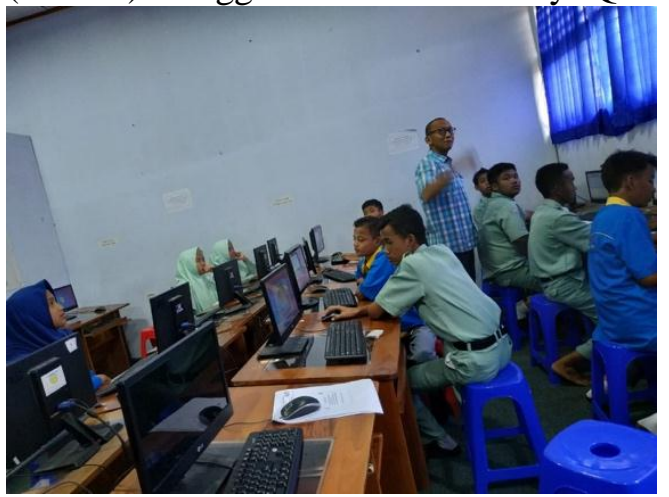

Gambar 2. Kegiatan pelatihan

Pelatihan dijadwalkan selama 7 kali pertemuan bertujuan agar siswa yang awam dengan komputer dapat mulai dilatih bagaimana menggunakan software aplikasi komputer dan menguasai Bahasa structured query language (SQL). Di awal pelatihan peserta pelatihan diberikan software aplikasi lalu dilakukan instalasi dan settingan agar para siswa dapat melakukannya secara mandiri. Setelah instalasi dan settingan aplikasi selesai seluruh siswa mempelajari Bahasabahasa SQL yang umum digunakan di semua DBMS. Disini para siswa diajarkan membuat sebuah database dan beberapa tabel yang disesuaikan dengan modul yang telah dibuat oleh tim pengabdian.

\section{SIMPULAN}

a. Pelatihan pengabdian masyarakat di SMK Muhammadiyah Salam Magelang ini bertujuan untuk mengenalkan software aplikasi kepada para siswa yang tujuan jangka panjanganya adalah untuk persiapan mengikuti LKS. Metode pelaksanaan dalam pengabdian masyarakat ini meliputi tahap perumusan masalah, tahap penentuan solusi, tahap pelaksanaan, tahap evaluasi, dan output.

b. Siswa yang megikuti pelatihan ini dapat membuat database, tabel dan menggunakan Bahasa SQL untuk selanjutnya pengembangan ke pelatihan selanjutnya yaitu pembuatan program aplikasi menggunakan Bahasa pemrogram Microsoft Visual .Net

\section{UCAPAN TERIMA KASIH}

Bagian ini boleh digunakan, boleh juga dihilangkan (opsional). Ucapan terima kasih hanya ditujukan pada pihak-pihak yang membantu secara langsung penelitian yang dilakukan, misal: penyan-dang dana atau pakar dilibatkan. Ucapan terima kasih tidak ditujukan untuk pejabat struktural, misalkan Ketua Jurusan, Dekan, ataupun Rektor.

\section{DAFTAR PUSTAKA}

Badri, M. (2016). Pembangunan Pedesaan Berbasis Teknologi Informasi Dan Komunikasi (Studi pada Gerakan Desa Membangun). RISALAH. Retrieved from http://ejournal.uinsuska.ac.id/index.php/risalah/article/vie $\mathrm{w} / 2514$

Duh, K., \& Kirchhoff, K. (2011). Semisupervised ranking for document retrieval. Computer Speech and Language, 25(2), 261-281. https://doi.org/10.1016/j.csl.2010.05.00 2 